\title{
Study on Evacuation Speed based on Psychological panic in Railway Tunnel
}

\author{
Li Qi $^{1}$, Cao Xiongzhi ${ }^{1}$, Xiong Xiaoling ${ }^{1}$, Yang Chang ${ }^{1 *}$ and Liao Xueling ${ }^{1}$ \\ ${ }^{1}$ School of Architecture and Urban-Rural Planning, Sichuan Agricultural University of organization, Chengdu, Sichuan
}

\begin{abstract}
In order to probe the panic psychology effect on the evacuation characteristics and evacuation efficiency under an emergency such as a fire in a railway tunnel, this paper uses a combination of theoretical derivation and 3D simulation technology to study personnel evacuation, investigates the psychological panic effect coefficient of the evacuation speed under various situations such as different numbers of personnel and structural parameters in emergency rescue evacuation facilities (emergency rescue stations, emergency exits, shelters) of railway tunnels to determine the range of influence factors of crowd evacuation speed under psychological panic. Studies show that: (1)Considering the effects of psychological panic factors, the speed of evacuation should increase by about 1.25 to 1.49 times, with an average of about 1.37 times; (2) The panic reduction factor for the crowd evacuation time at the emergency rescue station of the railway tunnel is $0.8 \sim 1$, and the panic reduction factor for the crowd evacuation time at the emergency exit and refuge is $0.75 \sim 1.05$.
\end{abstract}

\section{Introduction}

The railway tunnel is dark and long. Once an emergency such as a fire occurs in the railway tunnel, people need to get out of the train and evacuate. The environment of strange and fear will definitely cause psychological panic. Under the influence of panic psychology, the speed of evacuation of people will increase to varying degrees. Personnel in panic, the speed of individual evacuation is faster. For group evacuation, a certain degree of individual evacuation speed may increase the efficiency of crowd evacuation. However, if the evacuation speed of the individual is too large, the interaction between the individuals will increase significantly, which will cause pushing, collision, disorderly order, crowded exits, and serious aggregation during the evacuation process, which will reduce the evacuation efficiency ${ }^{1-2}$.

Helbing $D$ et al. ${ }^{3}$ used a modified social force model to consider the anxiety factor and studied the efficiency of evacuation in the room. It was found that when the anxiety factor is small, the increase of the anxiety factor will effectively improve the evacuation efficiency; Proulx $G^{4}$ and Kobes $M^{5}$ studied the relationship between the evacuation efficiency and the number of exits, the spatial layout of the building and other factors. It was found that the number of exits will increase the number of options for evacuation and panic. In some cases, there is a certain blindness in the choice of personnel, which leads to a decrease in evacuation efficiency; Farkas $I \mathrm{~J}$, et al. ${ }^{6}$ studied the parameters such as the time and speed of evacuation, and clarified that panic psychology can both promote and hinder the evacuation efficiency; Chen Changkun et al. ${ }^{7}$ studied the influence of panic mood on the behavior of crowds in evacuation and its regularity. Using cellular automata method, it was found that the number of panics was reduced, the evacuation time was reduced at the same time, and there was a critical value to make the evacuation time shortest.

In summary, panic psychology has a significant impact on the efficiency and time of evacuation. For the evacuation of people in a railway tunnel fire mode, it is even more necessary to study the factors of panic according to factors such as structural characteristics, evacuation routes, and evacuation numbers, determine the panic reduction factor suitable for the speed of crowd evacuation in a railway tunnel emergency (fire).

\section{Theoretical basis}

Under the influence of panic psychology, the evacuation speed of individuals will increase, and many scholars have also conducted related research. Among them, Predtechenskii and Milinskii ${ }^{8}$ proposed the evacuation speed relationship between personnel in emergency and non-emergency situations which is:

$$
V_{\mathrm{E}}=\mu_{\mathrm{E}} V_{0}
$$

In the formula: $V_{E}$ is the evacuation speed of people in emergency situations $(\mathrm{m} / \mathrm{s}) ; V_{0}$ is the evacuation speed of people in non-emergency situations $(\mathrm{m} / \mathrm{s}) ; \mu_{E}$ is the speed correction coefficient, $\mu_{E}=1.49-0.36 D_{0} ; D_{0}$ is the ratio of

*Corresponding author's e-mail: yangchang327@126.com. Postcode: 611830 Phone: 18224434624 
the projected area of the evacuated people to the ground area in the horizontal passage, which can be taken as 0.4 in the railway tunnel ${ }^{9}$.

Therefore, the ratio of the projected area of the evacuated person to the ground area is substituted into the formula for the speed correction factor in Equation (1), and the correction factor for the speed of evacuated persons in a high-speed railway tunnel fire mode in an emergency situation is approximately 1.346 to 1.49 .

People walk at different speeds in different mental states. When the psychological stress of a person is less than the critical degree, the passengers show orderly evacuation behavior; otherwise, the passengers show panic pressure behavior. Russian scholar Kholshevnikov et al. 10-11 carried out a series of research explorations between the psychological state and the movement behavior of personnel, and obtained the critical psychological pressure value of 0.7 when the person will experience panic behavior. The relationship between exercise style and walking speed under psychological stress is shown in Tab 1.

TABLE 1. Relationship between exercise style, psychological stress and free walking speed ${ }^{10}$

\begin{tabular}{ccccc}
\hline Level & Division of & Psychological & \multicolumn{2}{c}{$\begin{array}{c}\text { Free running } \\
\text { speed }(\mathbf{m} / \mathbf{s})\end{array}$} \\
\cline { 4 - 5 } & movement & stress & $\begin{array}{c}\text { Horizontal } \\
\text { channel }\end{array}$ & $\begin{array}{c}\text { Up } \\
\text { the } \\
\text { stairs }\end{array}$ \\
\hline I & Comfortable & 0.00 & 0.82 & 0.45 \\
II & Be quiet & $0.00-0.45$ & $0.82-1.10$ & $0.45-$ \\
& & & & 0.63 \\
III & Active & $0.45-0.68$ & $1.10-1.50$ & $0.63-$ \\
& Increased & & & 0.92 \\
IV & movement & $0.68-0.70$ & $1.50-2.00$ & $0.92-$ \\
& Psychological & & & 1.25 \\
V & stress & $>0.70$ & $2.00-2.50$ & $1.25-$ \\
& & & & 1.75 \\
\hline
\end{tabular}

It can be known from Tab 1 that the evacuation movement mode of the railway tunnel personnel in general is an exercise-increasing type (level IV), and in an emergency (fire), the evacuation environment will cause increased psychological pressure on the evacuation personnel. Considering psychological factors, the corresponding speed will increase, and its exercise method is a large psychological stress (level V). It can be calculated that the speed increase coefficient is about 1.25 $\sim 1.33$.

In summary, the speed of personnel evacuation in the fire mode, taking into account the effects of psychological panic factors, should increase approximately 1.25 to 1.49 times, with an average of approximately 1.37 times. According to the evacuation speed of the railway tunnel fire mode under the normal psychological conditions of different personnel ${ }^{12}$, and considering the psychological panic factors of the personnel, the emergency evacuation speed of different types of personnel under the influence of panic in the tunnel is variable, as shown in Tab 2.
TABLE 2. Values of evacuation speed for different types of personnel considering psychological panic

\begin{tabular}{ccccc}
\hline Person type & Child & $\begin{array}{c}\text { Adult } \\
\text { male }\end{array}$ & $\begin{array}{c}\text { Adult } \\
\text { woman }\end{array}$ & Seniors \\
\hline $\begin{array}{c}\text { Evacuation } \\
\text { speed of }\end{array}$ & & & & \\
people in \\
railway & 0.67 & 1 & 0.8 & 0.6 \\
tunnel fire \\
$\quad$ mode \\
$\quad$ m/s $)$
\end{tabular}

\section{Research Method}

To simulate the evacuation of personnel at emergency rescue stations and emergency exits in railway tunnels, a personnel evacuation model which with different evacuation numbers and structural parameter combinations was constructed by EXDOUS-building personnel evacuation 3D simulation technology. Then, the total time required for evacuation was collected when the psychological effect of panic was considered and the psychological effect of panic was not considered.

The emergency rescue station is a designated parking evacuation rescue point inside the railway tunnel. In Fig 1, the structure of emergency rescue station is shown. There are multiple evacuation passage-ways in the emergency rescue station for people to escape from the accident tunnel. Each passage-way can be used for the evacuation of passengers in 1 to 2 cars. The primary relevant parameters established by the evacuation model in the emergency rescue station are the number of passengers in 1 carriage, the platform width, the distance between the transverse passages, and the width of the transverse passage protection door, etc. The emergency exit is a random parking evacuation rescue point inside the railway tunnel. In Fig 2, the structure of emergency exit is shown. There is only one exit at the emergency exit for all train personnel to evacuate from the accident tunnel. The primary relevant parameters established by the evacuation model in the emergency exit are 1 car number, total train number, running surface width, train length, exit guard gate width, etc.

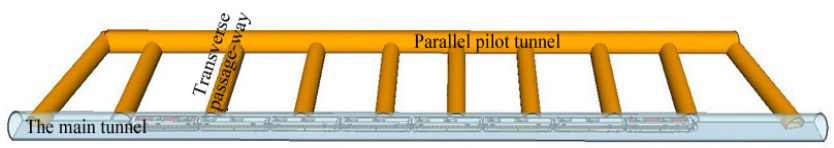

Figure 1. Schematic diagram of emergency rescue station 


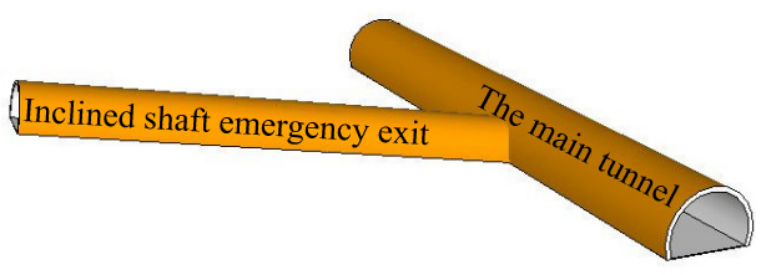

Figure 2. Emergency exit structure diagrams

The evacuation time analysis of emergency rescue stations and emergency exits under different parameters was carried out using Orthogonal Experimental Design methods. Orthogonal Experiment Design is a design method that studies multi-factor and multi-level variables. Orthogonal design experiments are based on orthogonality, and some representative points are selected from the comprehensive experiments for experiments. These representative points have the characteristics of uniform dispersion, neat and comparable ${ }^{13}$. The orthogonal experiment design is mainly divided into the following three steps. First, determine the factors and levels of the trial. Second, build the right orthogonal table; third, design the test plan and list the test results ${ }^{14}$. According to the steps of orthogonal experiment design, it is determined that the number of working conditions established by the emergency evacuation station and emergency exit personnel evacuation model is 24 and 17.The specific working conditions are shown in Tab 3.

\section{Research results and analysis}

Considering the psychological panic factors of personnel, the numerical simulation calculation of the required safety egress time of the high-speed railway tunnel is performed. The calculation results are compared with the required safety egress time without considering the psychological panic factor of the personnel. Results and comparisons of emergency evacuation time at emergency rescue stations are shown in Tab 3. Results and comparison of emergency evacuation time for emergency exit and refuge are shown in Tab 4.

TABLE 3. Required safety egress time considering panic factors in emergency rescue station

\begin{tabular}{|c|c|c|c|c|c|c|c|}
\hline \multirow[b]{2}{*}{$\begin{array}{c}\text { Serial } \\
\text { number }\end{array}$} & \multirow{2}{*}{$\begin{array}{c}\text { Maximum } \\
\text { number } \\
\text { of people } \\
\text { in one } \\
\text { carriage } \\
\text { (person) }\end{array}$} & \multirow[b]{2}{*}{$\begin{array}{l}\text { Platform } \\
\text { width } \\
\text { (m) }\end{array}$} & \multirow{2}{*}{$\begin{array}{l}\text { Cross } \\
\text { channel } \\
\text { spacing } \\
\text { (m) }\end{array}$} & \multirow{2}{*}{$\begin{array}{c}\text { Cross } \\
\text { aisle } \\
\text { protective } \\
\text { door } \\
\text { width } \\
\text { (m) }\end{array}$} & \multicolumn{3}{|c|}{$\begin{array}{l}\text { Emergency rescue station must be } \\
\text { safely evacuated }(\mathrm{s})\end{array}$} \\
\hline & & & & & $\begin{array}{c}\text { Not } \\
\text { considering } \\
\text { psychological } \\
\text { panic }\end{array}$ & $\begin{array}{c}\text { Considering } \\
\text { psychological } \\
\text { panic }\end{array}$ & Ratio \\
\hline 1 & 80 & 1.5 & 50 & 1.5 & 161 & 143 & 0.89 \\
\hline 2 & 80 & 2.5 & 70 & 1.5 & 189 & 165 & 0.87 \\
\hline 3 & 80 & 3 & 80 & 2 & 154 & 126 & $\begin{array}{l}0.01 \\
0.82\end{array}$ \\
\hline 4 & 80 & 2 & 60 & 2.5 & 137 & 113 & 0.82 \\
\hline 5 & 80 & 2.5 & 70 & 3.5 & 143 & 125 & 0.87 \\
\hline 6 & 80 & 3 & 80 & 4.5 & 138 & 123 & 0.89 \\
\hline 7 & 120 & 1.5 & 60 & 1.5 & 248 & 218 & 0.88 \\
\hline 8 & 120 & 2 & 50 & 2 & 184 & 156 & 0.85 \\
\hline 9 & 120 & 1.5 & 60 & 3.5 & 190 & 153 & 0.81 \\
\hline 10 & 120 & 2 & 50 & 4.5 & 163 & 145 & 0.89 \\
\hline 11 & 120 & 2.5 & 80 & 1.5 & 290 & $\begin{array}{l}253 \\
258\end{array}$ & $\begin{array}{l}0.89 \\
0.89\end{array}$ \\
\hline 12 & 120 & 3 & 70 & 2.5 & 193 & 168 & 0.87 \\
\hline 13 & 160 & 1.5 & 70 & 2 & 295 & 266 & 0.90 \\
\hline 14 & 160 & 2 & 80 & 1.5 & 378 & 352 & 0.93 \\
\hline 15 & 160 & 3 & 60 & & 448 & 414 & 0.92 \\
\hline 16 & 160 & 2 & 80 & 3.5 & 255 & 214 & 0.84 \\
\hline 17 & 160 & 2.5 & 50 & 2.5 & 212 & 179 & 0.85 \\
\hline 18 & 160 & 3 & 60 & 1.5 & 310 & 291 & 0.94 \\
\hline 19 & 200 & 2 & 70 & 1 & 628 & 617 & 0.98 \\
\hline 20 & 200 & 2.5 & 60 & 2 & 308 & 298 & 0.97 \\
\hline 21 & 200 & 1.5 & 80 & 2.5 & 312 & 273 & 0.87 \\
\hline 22 & 200 & 2 & 70 & 1.5 & 428 & 413 & 0.97 \\
\hline 23 & 200 & 2.5 & 60 & 4.5 & 255 & 227 & 0.89 \\
\hline 24 & 200 & 3 & 50 & 3.5 & 239 & 212 & 0.89 \\
\hline
\end{tabular}

TABLE 4. Required safety egress time considering panic factors in emergency exit and refuge

\begin{tabular}{|c|c|c|c|c|c|c|c|c|}
\hline \multirow[b]{2}{*}{$\begin{array}{c}\text { Serial } \\
\text { number }\end{array}$} & \multirow{2}{*}{$\begin{array}{c}\text { Maximum } \\
\text { number } \\
\text { of people } \\
\text { in one } \\
\text { carriage } \\
\text { (person) }\end{array}$} & \multirow{2}{*}{$\begin{array}{c}\text { Total } \\
\text { number } \\
\text { of people } \\
\text { evacuated } \\
\text { (person) }\end{array}$} & \multirow{2}{*}{$\begin{array}{l}\text { Running } \\
\text { surface } \\
\text { width } \\
(\mathbf{m})\end{array}$} & \multirow{2}{*}{$\begin{array}{l}\text { Train } \\
\text { length } \\
\text { ( } \mathbf{m})\end{array}$} & \multirow{2}{*}{$\begin{array}{c}\text { Exit } \\
\text { protection } \\
\text { door } \\
\text { width } \\
(\mathrm{m})\end{array}$} & \multicolumn{3}{|c|}{$\begin{array}{l}\text { Emergency evacuation time } \\
\text { required for safe evacuation ( } s \text { ) }\end{array}$} \\
\hline & & & & & & $\begin{array}{c}\text { Not } \\
\text { considering } \\
\text { psychological } \\
\text { panic }\end{array}$ & $\begin{array}{c}\text { Considering } \\
\text { psychological } \\
\text { panic }\end{array}$ & Ratio \\
\hline 1 & 80 & 1440 & 1 & 500 & 2 & 728 & 581 & 0.80 \\
\hline 2 & 80 & 640 & 1.5 & 200 & 1.5 & 308 & 289 & 0.94 \\
\hline 3 & 80 & 880 & 2 & 300 & 2.5 & 368 & 300 & 0.82 \\
\hline 4 & 80 & 1440 & 1 & 500 & 4.5 & 728 & 551 & 0.76 \\
\hline 5 & 100 & 1100 & 1.5 & 300 & 1 & 819 & 780 & 0.95 \\
\hline 6 & 100 & 800 & 2 & 200 & 2 & 289 & 257 & 0.89 \\
\hline 7 & 100 & 1100 & 1.5 & 300 & 3.5 & 382 & 302 & 0.79 \\
\hline 8 & 100 & 800 & 2 & 200 & 4.5 & 281 & 223 & 0.80 \\
\hline 9 & 100 & 1500 & 1 & 400 & 2.5 & 620 & 510 & 0.82 \\
\hline 10 & 120 & 1800 & 1.5 & 400 & 2 & 648 & 635 & 0.98 \\
\hline 11 & 120 & 2160 & 2 & 500 & 1 & 1549 & 1630 & 1.05 \\
\hline 12 & 120 & 1800 & 1.5 & 400 & 4.5 & 620 & $\begin{array}{l}485 \\
485\end{array}$ & 0.78 \\
\hline 13 & 120 & 2160 & 2 & 500 & 3.5 & 617 & 464 & 0.75 \\
\hline 14 & 120 & 1320 & 1 & 300 & 1.5 & 823 & 760 & 0.92 \\
\hline 15 & 140 & 1120 & 1 & 200 & 1 & 1144 & 1137 & 0.99 \\
\hline 16 & 140 & 2520 & 1.5 & 500 & 2.5 & 758 & 719 & 0.95 \\
\hline 17 & 140 & 2100 & 2 & 400 & 1.5 & 998 & 1045 & 1.05 \\
\hline
\end{tabular}

According to tables 3 and 4, when the factor of psychological panic is considered, the evacuation time of personnel will be reduced or increased to varying degrees according to different parameters, such as the number of personnel. The panic reduction factor for egress time of emergency rescue station $(\varepsilon 1)$ is between 0.8 and 1 . The panic reduction factor for egress time of emergency exit or refuge ( $\varepsilon 2)$ is between 0.75 and 1.05 . The above results indicate that psychological panic at emergency exits and refuge has a greater impact on the egress time. The recommended value of the evacuation panic factor for high-speed railway tunnel personnel is shown in Tab 5.

TABLE 5. The value of the evacuation panic factor for railway tunnel $(\varepsilon)$

\begin{tabular}{cccccc}
\hline Type of rescue facility & \multicolumn{2}{c}{ Emergency rescue station } & \multicolumn{4}{c}{ Emergency exit, refuge } \\
Exit width $(\mathbf{m})$ & $<\mathbf{2 . 5}$ & $\geq \mathbf{2 . 5}$ & $\mathbf{1 . 5}$ & $\mathbf{1 . 5} \mathbf{2 . 5}$ & $\geq \mathbf{2 . 5}$ \\
\hline $\begin{array}{c}\text { Maximum number of single } \\
\text { cars } \leq 120\end{array}$ & $0.8 \sim 0.9$ & $0.8 \sim 0.9$ & -- & -- & -- \\
$\begin{array}{c}\text { Maximum number of single } \\
\text { carriages }>120\end{array}$ & $0.9 \sim 1.0$ & $0.8 \sim 0.9$ & -- & -- & -- \\
$\begin{array}{c}\text { Total number of evacuation } \\
\quad \leq 1500\end{array}$ & -- & -- & $0.9 \sim 1.0$ & $0.8 \sim 0.9$ & $0.75 \sim 0.85$ \\
$\begin{array}{c}\text { Total number of } \\
\text { evacuation> }>1500\end{array}$ & -- & -- & $1.0 \sim 1.05$ & $0.9 \sim 1.0$ & $0.75 \sim 0.95$ \\
\hline
\end{tabular}

\section{Conclusion}

By studying the speed and time of evacuation under the influence of panic psychology, the following main conclusions are obtained:

(1) Considering the effects of psychological panic factors, the speed of evacuation should increase by about 1.25 to 1.49 times, with an average of about 1.37 times;

(2) The panic reduction factor for egress time of emergency rescue station is between 0.8 and 1 . The panic reduction factor for egress time of emergency exit or refuge is between 0.75 and 1.05 .

\section{Acknowledgment}

National Natural Science Foundation of China (51908387); Sichuan Agricultural University Scientific Research Interest Cultivation Project (2020804)

\section{References}

1. DENG Yujing, FENG Yexin, HU Liege. (2014) The Impact of Psychology and Randomness on the Crowd Evacuation of Pedestrians: A 
Modification of Social Force Model. Systems Engineering, 32 (11): 144-148.

2. Suh W. (2013) Modeling pedestrian crossing activities in an urban environment using microscopic traffic simulation. Simulation, 89 (2):213-224

3. Helbing D. (2000) Simulating dynamical features of escape panic. Nature, 407(6803):487-490.

4. Proulx G. (2001) Occupant behavior and evacuation. Nation-al Research Council Canada, Canada.

5. Kobes M, Helsloot I, Vries B D, et al. (2010) Building safety and human behavior in fire: A literature review. Fire Safety Journal,45(1):134142.

6. Helbing D, Farkas I J, Molnar P, et al. (2002) Simulation of Pedestrian Crowds in Normal and Evacuation Simulations. Pedestrian and Evacuation Dynamics.

7. CHEN Changkun, TONG Yunhe. (2019) Study on crowd evacuation model under panic state based on cellular automata. Journal of Safety Science and Technology, 15 (6): 12-17.

8. Predtechenskii V.M., Milinskii A.I. (1978) Planning for Foot Traffic Flow in Buildings. Amerind Publishing Co. Pvt. Ltd.

9. LI QI. (2017) RESEARCH ON RELIABILITY OF PERSONNEL SAFE EVACUATION
UNDER HIGH-SPEED RAILWAY SUPERLONG TUNNEL IN FIRE. Southwest Jiaotong University Doctor Degree Dissertation.

10. Kholshevnikov VV. (1999) The study of human flows and methodology of evacuation standardisation. Moscow: MIFS.

11. Kholshevnikov VV. (1983) Human flows in buildings, structures and on their adjoining territories $[\mathrm{C}]$.Doctor of science thesis. Moscow: MISI.

12. LI Qi, WANG Mingnian, YU Li. (2015) Structure Parameters of Entrance Section of Shaft Type Emergency Exit in Railway Tunnel. CHINA RAILWAY SCIENCE, 36(5):36-42.

13. FANG Kaitai, MA Changxing. (2001) Orthogonal and Uniform Experimental Design. Science Press, China.

14. DONG Hehe, XIAO Bihua, FANG Yongshui. (2004) THE THEORETICAL ANALYSIS OF ORTHOGONAL TEST DESIGNS. Journal of Anhui Institute of Architecture and Industry (Natural Science Edition), 12 (6): 103-106.

15. Burstedde C. (2001) Simulation of pedestrian dynamics using a two-dimensional cellular automation. Statistical Mechanics and its Applications, 295 (3):507-525. 